\title{
Full scale experiments on the effectiveness of a drainage system for cemented paste backfill
}

\author{
A. Hasan School of Civil and Resource Engineering, The University of Western Australia, Australia \\ G. Suazo School of Civil and Resource Engineering, The University of Western Australia, Australia
}

A.B. Fourie School of Civil and Resource Engineering, The University of Western Australia, Australia

\begin{abstract}
This paper presents full-scale experiments on cemented paste backfilling in two operating mine stopes located at Raleigh mine, Kalgoorlie, Western Australia. The experiments compared the behaviour of the cemented paste backfill (CPB) in a drained stope and an undrained stope. The drained stope was equipped with a drainage system at the barricade, whereas the undrained stope was not. Total stress and pore water pressure sensors were installed to measure the stress within the fill mass during and after backfilling. The stress behaviour was expressed by the normalised total horizontal pressure and the normalised pore water pressure. It was found that the normalised total horizontal pressure and the normalised pore water pressure behaviour at the two stopes were significantly different. The drainage system increased the consolidation of the fill and reduced the pressure acting on the barricade. The pore water pressure measurement in the undrained stope showed a non-linear accumulation at the barricade. In contrast with the undrained stope, the stope with the drainage system showed significant pore water pressure reduction and the accumulation of pore water pressure at the barricade no longer occurred. The findings described in the paper contribute to critical design and management aspects such as barricade stress, filling rate, and curing strategy, with an ultimate goal of reducing costs while ensuring safety underground.
\end{abstract}

\section{Introduction}

Since its first use in Bad Grund Mine, Germany (Potvin et al., 2005), CPB has become increasingly employed in mine backfilling over the past decade (Helinski et al., 2011). For mining companies, CPB is a good management strategy to make use of waste products (tailings) from mill processing plants for improving the underground strength and stability, and also to maximise ore extraction (Sivakugan et al., 2006). In Australia and Canada, its application was not really successful until mid-1990. Since then, several successful paste plant operations have adopted CPB technology, providing development and innovations (Rankine and Sivakugan, 2007; Potvin et al., 2005).

CPB refers to full stream tailings (in some cases the tailings are de-slimed) transported hydraulically via reticulation pipes to fill mined-out voids (stopes). The tailings are mixed with binder and water to form paste-consistency material. The typical solid content (weight of solids per total weight) is between $75 \%$ and $85 \%$. A binder such as Portland cement is the key component of CPB in order for it to achieve enough strength to be a self-supporting material soon after the filling is completed (Le Roux et al., 2005; Landriault et al., 2000; Thompson et al., 2009). The binder usage is normally between $1 \%$ and $8 \%$ of the solid content by weight. The strength property is sometimes augmented by blending CPB with fine aggregate (e.g. sand), pozzolanic material and chemical admixtures (Landriault et al., 2000; Thompson et al., 2009).

The fine particles and the retained water allow the paste to flow as homogeneous slurry. Due to its ability to retain water, CPB has different characteristics than other forms of backfill such as hydraulic fill. Consolidation takes place at the same time as the cement hydration process. The use of relatively fine tailings poses some challenges during and after backfilling due to the low permeability of the CPB.

Amongst its advantages, CPB can achieve rapid strength gain compared to other types of backfill, resulting in a faster production time, which increases cost savings and hence profitability. Furthermore, CPB 
generates very little excess water (i.e. bleed) compared to hydraulic backfill and remains as a homogeneous material throughout the filling process. However, there are still challenges related to the time needed to remove the excess water (unhydrated). The accumulated excess water not only contributes to high geostatic stresses during and after filling, but also poses risks such as liquefaction and fill-runs. The use of a drainage system was proposed to reduce the build-up of pore water pressure within the stope and, more importantly, behind the barricade. This technique is commonly used in hydraulic backfill and composite backfill to drain large quantities of seepage or decanted water through the barricade, but has not always been used with CPB systems. The reduction of the pore water pressure is equivalent to an increase of the effective stress. Increases in effective stress will not only help in reducing the barricade strength but will also improve the CPB strength (Fahey et al., 2011).

There are few full-scale observations of CPB behaviour published (e.g. Landriault et al., 2000; Belem et al., 2004; Grabinsky and Bawden, 2007; Thompson et al., 2009). The geomechanical design of CPB systems (in the field) has borrowed from experiences with other forms of backfilling (Grabinsky and Bawden, 2007). For example, some mining operations conduct the filling process in stages (fill and pause) instead of filling continuously. This is mainly to limit the stress acting on the barricade during filling and also to achieve enough strength in the first CPB layer (during the pause period) so that it can plug the draw point and reduce the stress imposed on the barricade during later filling stages. It is believed that further measurements of full-scale performance are critical to ensure improvements in current design procedures.

This paper presents in situ measurements of the behaviour of CPB during and after backfilling in two operating stopes at the Raleigh mine, Kalgoorlie, Western Australia. The two stopes were similar but have different drainage conditions. In one stope, drainage was installed at the barricade, but not the other. The paper discusses the effectiveness of installing drainage to reduce the total stress imposed at the barricade, i.e. by allowing excess water to drain through the barricade such that the CPB can gain an early increase in effective stress.

\section{Methodology}

The field instrumentation was carried out in collaboration with Barrick (Australia Pacific) Limited. Two operating stopes were instrumented. The stoping was carried out in retreat mode. The available time for instrumentation installation was limited, sandwiched between ore removal and installation of the barricade. The first instrumentation was conducted in stope 5795 panel 74 (stope 1) and the second instrumentation was in stope 5795 panel 78 (stope 2). There was a two-month time-gap between the two studies. Both stopes were located at the same underground level, separated by one stope (5795 panel 76) between the two instrumented stopes.

\subsection{Stope geometry}

The two stopes have average dimensions of $17 \mathrm{~m}$ in height, $18 \mathrm{~m}$ in length, and $3.5 \mathrm{~m}$ width. Stopes 1 and 2 incline at approximately $65^{\circ}$ and $70^{\circ}$ to the horizontal (width), respectively. There are two access driveways, at the top and at the bottom. The access driveways are only accessible on one side (since stoping is a retreat mode). The dimension of the two driveways is approximately $3 \mathrm{~m}$ wide and $3 \mathrm{~m}$ high. The barricade was installed approximately $3.5 \mathrm{~m}$ from the drawpoint (brow) in the bottom driveway. Figure 1 shows the geometry of the two stopes obtained from Cavity Monitoring System (CMS) data. The area enclosed by the facets is the voids (stopes). It is shown that there were two unblasted rock segments existing at the top of stope 1 and one unblasted rock segment at the top of stope 2 . The incoming direction of the access driveways is from the positive $x$-axes to the negative $x$-axes. 
(a)
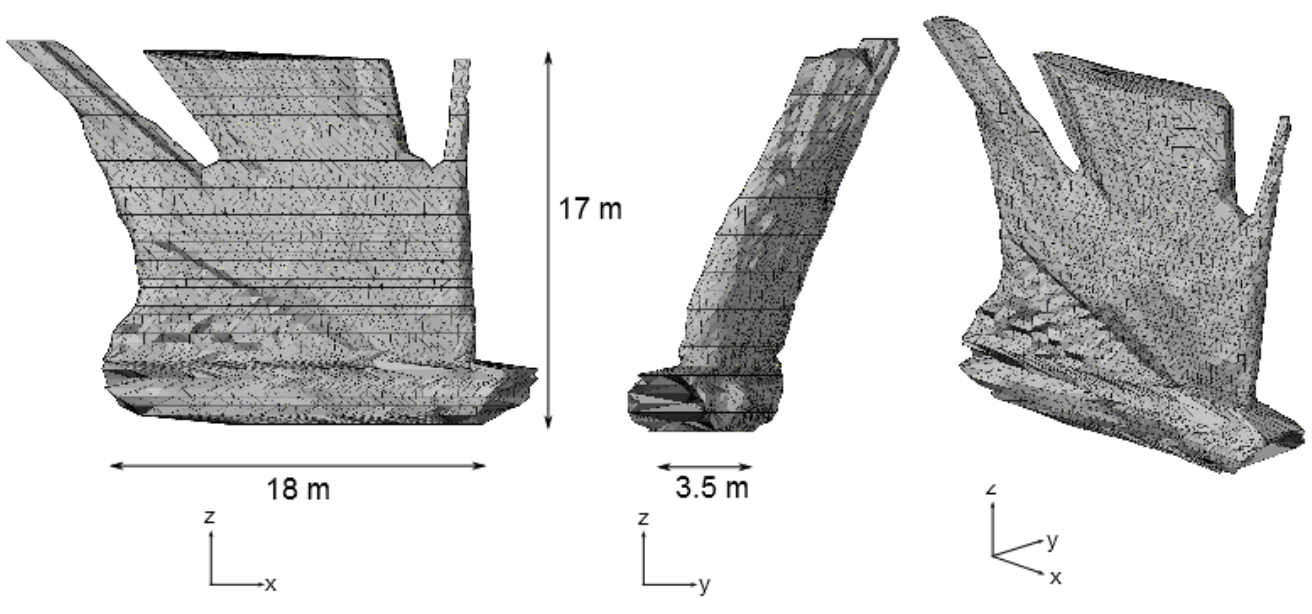

(b)
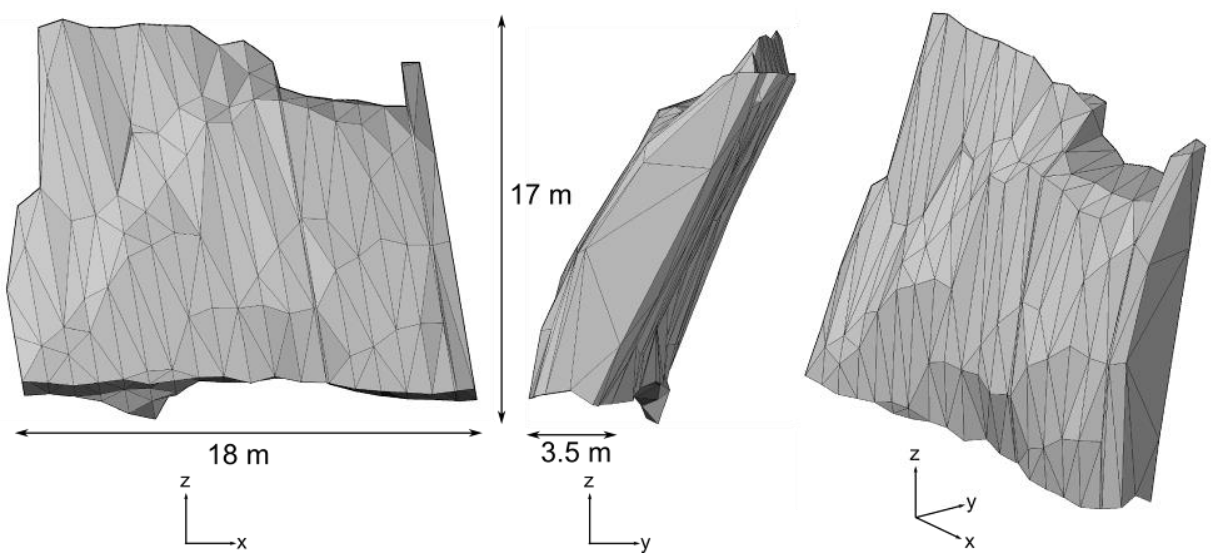

Figure 1 (a) The geometry of stope 1; (b) the geometry of stope 2

\section{$2.2 \quad$ Instrumentation}

Instruments for measuring total horizontal pressure and pore water pressure were installed in both stopes. Total horizontal pressure was measured by NATM stress cells (Geokon model number 4850NPST-1$700 \mathrm{kPa}$ ), a thin rectangular cell measuring $10 \times 20 \mathrm{~mm}$, capable of reading up to $700 \mathrm{kPa}$ (resolution of $\pm 0.025 \%$ and accuracy of $\pm 0.1 \%$ ) of total pressure. The stress cell is designed for concrete tunnelling, equipped with a pinch-tube to re-pressurise the cell liquid (to avoid under-registration for long term measurement). However, this feature was unused since the entire sensors were embedded in the paste. The cell is made from stiff plates to minimise under-registration during CPB stiffness increase (Fourie et al., 2007). Figures 2 (a) and 2(b) show the picture of the top access drive and the inside of stope. The NATM stress cell is shown in Figure 2(c). 


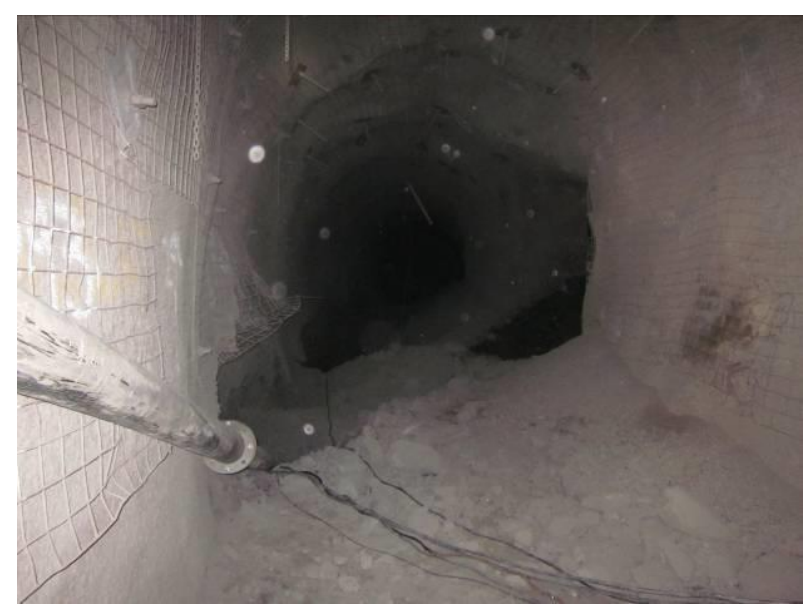

(a)

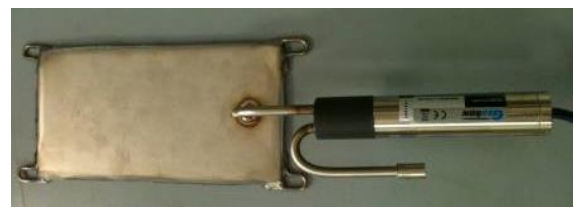

(c)

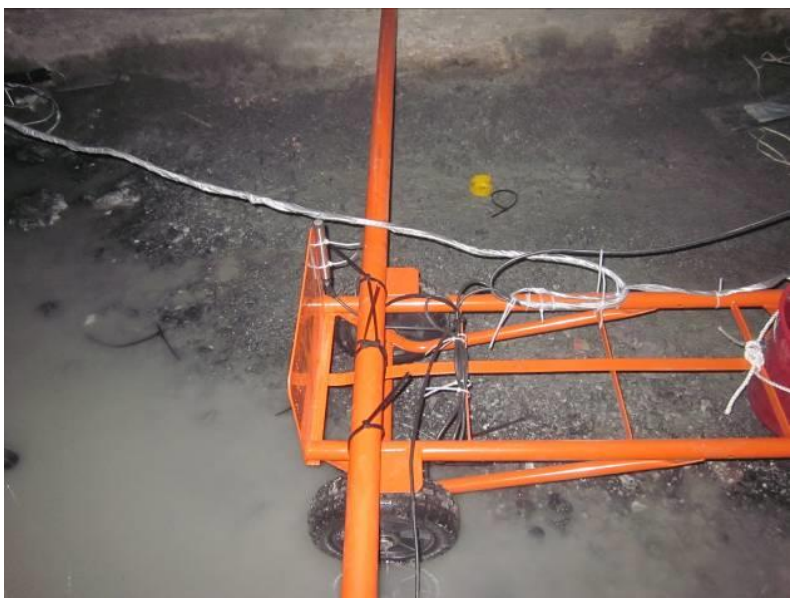

(e)

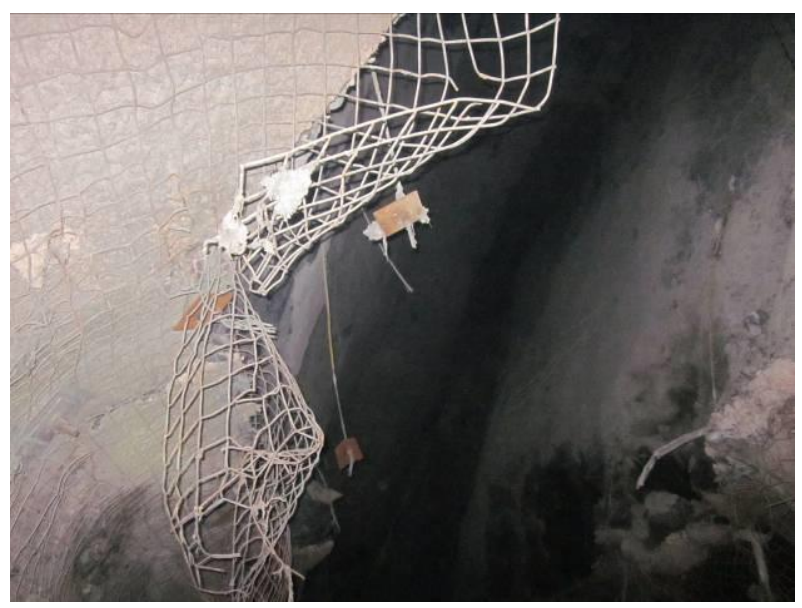

(b)

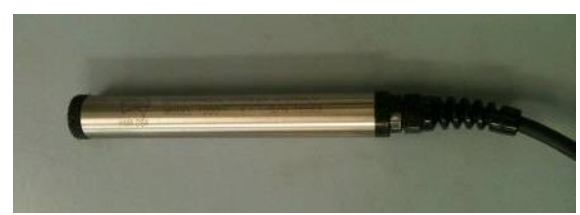

(d)

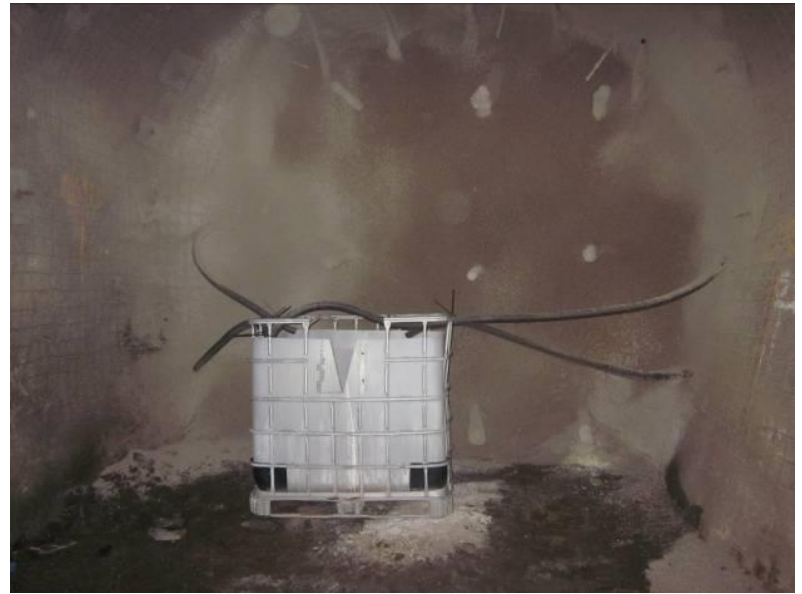

(f)

Figure 2 (a) Top drive, paste pipe and sensors cables; (b) Narrow and inclined stope; (c) NATM stress cell; (d) Vibrating wire piezometer; (e) Trolley with a piezometer; (f) Water tank in front of the barricade to collect drained water from the stope

It is worth emphasising that the reliable measurement of soil pressure within deforming soil mass is a challenging task and, to date, no reliable device to monitor the magnitude of soil pressure has been widely accepted (Talesnick, 2004). The flexibility ratio (Clayton and Bica, 1993) and cell action factor (Taylor, 1947) have been used to quantify error measurement in soil pressure cells, which is a function of both the soil and cell stiffness and the Poisson's ratio of the soils. Therefore, pressure measurements within a continuum, particularly one undergoing stiffness change due to consolidation and cementation, can only be treated as an indication of the true soil pressure (Helinski et al., 2011).

The pore water pressure was measured by vibrating wire piezometers (Geokon model number $1200-700 \mathrm{kPa}$ ) with up to $700 \mathrm{kPa}$ (resolution of $\pm 0.025 \%$ and accuracy of $\pm 0.5 \%$ ) pressure ranges. The piezometer is shown in Figure 2(d). The stress cell and piezometer sensors contain a thermistor to measure temperature, to be used to correct the frequency reading based on manufacturer calibrations. Sensors were connected to multichannel data logger (Datataker model DT80). 
The sensors were placed in two locations: at the base of the stope (location 1) and at the barricade (location 2). The locations are the same both in stope 1 and stope 2. Location 1 was about $6 \mathrm{~m}$ horizontal distance from the drawpoint (brow). One piezometer was placed at the base (location 1) and one at the barricade (location 2). In addition, one stress cell was placed at the barricade (the inner side). The piezometer for location 1 was fixed to a trolley. The piezometer position is about $40 \mathrm{~cm}$ from the ground. Figure 2(e) shows the trolley and the piezometer prepared next to the instrumented stope. All sensor cables were pulled to the top drive using a rope, secured and connected to the data logger. The data logger was placed at the top driveway to avoid disturbance. The trolley was then pushed to location 1 using PVC pipes. At location 2, the stress cell and the piezometer at the barricade were fixed to the frame during barricade installation prior to spraying a shotcrete layer. Their positions were at the centre of the barricade. Figure 3 illustrates the location of the sensors inside the stope.

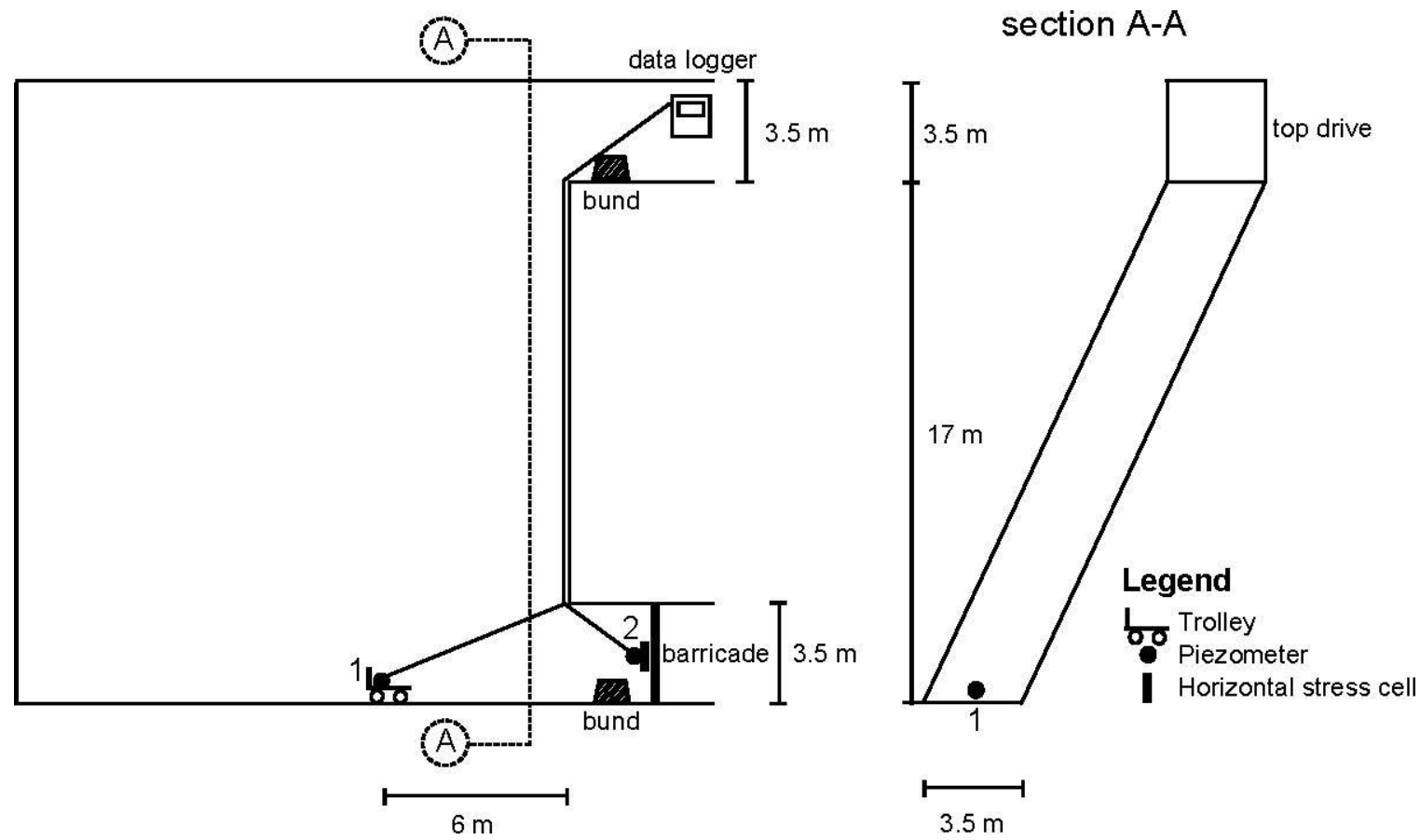

Figure 3 Sensor locations inside stope 1 and stope 2

In stope 2, drainage access was installed passing through the barricade using four agricultural perforated pipes. The diameter of the pipes was $10 \mathrm{~cm}$. One end of the pipes (inside the stope) was wrapped with special cloth (socks) to prevent loss of the CPB solids. Figure 4 illustrates the installation of the drainage pipes at the barricade. The pipes were fixed at the barricade before spraying the barricade with shotcrete. They were extended by non-perforated pipes and routed to a 1,000 litre water tank to collect drained water. Figure 2(f) shows the drainage pipes with the water tank after installation. Note that the V-notch at the front of the water tank was used to discharge excess drained water from the tank. 


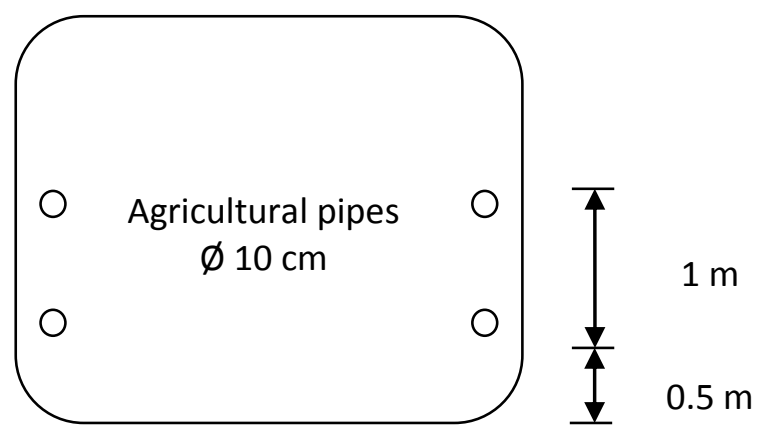

Front-view of the barricade

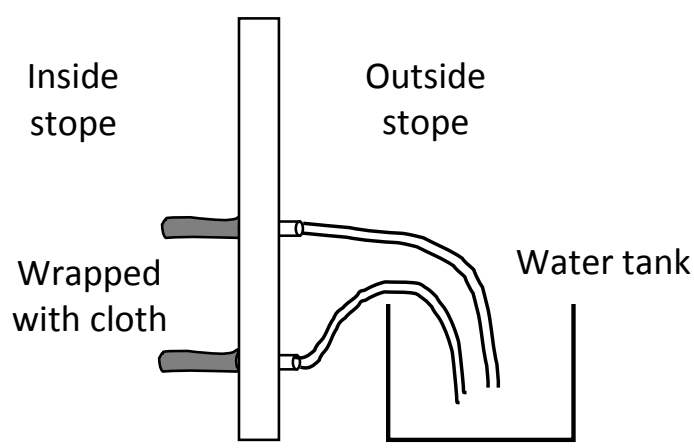

Side-view of the barricade

Figure 4 Drainage pipes in stope 2

\subsection{Backfilling}

The reticulation pipe pressure was controlled to prevent over-pressurisation and the flow was maintained at an average filling rate of about $100-110 \mathrm{~m}^{3} / \mathrm{hr}$, giving an average rate of rise of $1.7 \mathrm{~m} / \mathrm{hr}$. To achieve good flow, the CPB rheology was measured by the slump test. The average slump of the CPB before filling (taken at the plant) was about $70 \mathrm{~mm}$ using a $100 \mathrm{~mm}$ cylinder mould. In addition to slump test, the yield stress tests were also conducted. The stopes had a volume of approximately $1,000 \mathrm{~m}^{3}$. Therefore, with an average rate of rise (accretion) of $1.7 \mathrm{~m} / \mathrm{hr}$, the filling took in total of approximately 10 hours to complete (for each stope) and the filling was not able to be done continuously. To avoid blockage of the pipes, flushing was carried out after each filling with $3 \mathrm{~m}^{3}$ (3,000 litres) of water combined with $600 \mathrm{kPa}$ of air pressure.

The condition of the floor and walls of the stopes prior to filling was relatively dry, i.e. no significant presence of ground water. The filling for stope 1 was conducted in two stages, with about $40 \%$ of the stope volume being filled during the first stage. The estimated fill height was approximately $6 \mathrm{~m}$ from the base. The second stage filling was conducted the following day. There was a 17 hour pause period between the two stages. Stope 2 was filled in three stages. The rate of filling was varied from $100-110 \mathrm{~m}^{3} / \mathrm{hr}$. The pause period between each stage was about 17 hours. In the first stage, $142 \mathrm{~m}^{3}$ of paste was filled (12\% of the total), in the second stage $73.7 \mathrm{~m}^{3}$ paste was filled (74\% of the total), and in the last stage $151 \mathrm{~m}^{3}$ paste was filled ( $14 \%$ of the total).

The details of the operational data including QA/QC are given in Table 1 and Table 2 for stope 1 and stope 2 , respectively.

Table 1 Operational data and QA/QC of paste filling for stope 1 (June, 2012)

\begin{tabular}{lcccccccc}
\hline Date & \multicolumn{3}{c}{ 07/06/2012 } & \multicolumn{7}{c}{$\mathbf{0 8 / 0 6 / 2 0 1 2}$} \\
\hline Time & $14: 00$ & $15: 00$ & $16: 00$ & $11: 00$ & $12: 00$ & $13: 00$ & $14: 00$ & $15: 00$ \\
Paste flow rate (m) $\mathbf{h r})$ & 110 & 110 & 110 & 110 & 110 & 110 & 110 & 110 \\
Solid content (\%) & 74.0 & 74.4 & 74.5 & 74.8 & 75.2 & 74.8 & 75.1 & 75.1 \\
Paste Yield Stress (Pa) & 220 & 240 & 300 & 260 & 280 & 280 & 266 & 266 \\
Cement content (\%) & 5.0 & 5.0 & 5.0 & 4.0 & 4.0 & 4.0 & 4.0 & 4.0 \\
Sands Ratio (\%) & 30 & 30 & 30 & 30 & 30 & 30 & 30 & 30 \\
Sands Moisture (\%) & 7.00 & 7.00 & 7.00 & 7.00 & 7.00 & 7.00 & 7.00 & 7.00 \\
Tailings Ratio (\%) & 70 & 70 & 70 & 70 & 70 & 70 & 70 & 70 \\
Tailings Moisture (\%) & 11.00 & 11.00 & 11.00 & 11.00 & 11.00 & 11.00 & 11.00 & 11.00 \\
\hline
\end{tabular}


Table 2 Operational data and QA/QC of paste filling for stope 2 (August 2012)

\begin{tabular}{lcccccccccccc}
\hline & $\mathbf{0 2 / 0 8 / 2 0 1 2}$ & & \multicolumn{7}{c}{$\mathbf{0 3 / 0 8 / 2 0 1 2}$} & & & $\mathbf{0 4 / 0 8 / 2 0 1 2}$ \\
\hline Date & $13: 00$ & $10: 00$ & $11: 00$ & $12: 00$ & $13: 00$ & $14: 00$ & $15: 00$ & $16: 00$ & $17: 00$ & $11: 00$ \\
\hline $\begin{array}{l}\text { Paste flow rate } \\
\text { (m) }\end{array}$ & 110 & 105 & 100 & 100 & 105 & 105 & 105 & 105 & 105 & 100 \\
$\begin{array}{l}\text { Solid content (\%) } \\
\text { Paste yield stress }\end{array}$ & 74.6 & 74.4 & 74.5 & 74.7 & 75.1 & 74.6 & 74.5 & 74 & 74.4 & 73.5 \\
$\begin{array}{l}\text { (Pa) } \\
\text { Cement content }\end{array}$ & 245 & 250 & 250 & 200 & 220 & 200 & 200 & 200 & 200 & 228 \\
$\begin{array}{l}\text { (\%) } \\
\text { Sands ratio (\%) }\end{array}$ & 5.0 & 5.0 & 5.0 & 4.0 & 4.0 & 4.0 & 4.0 & 4.0 & 4.0 & 4.0 \\
$\begin{array}{l}\text { Sands moisture } \\
\text { (\%) }\end{array}$ & 7.0 & 7.0 & 7.0 & 7.0 & 7.0 & 7.0 & 7.0 & 7.0 & 7.0 & 7.0 \\
$\begin{array}{l}\text { Tailings ratio (\%) } \\
\text { Tailings moisture }\end{array}$ & 70 & 70 & 70 & 70 & 70 & 70 & 70 & 70 & 70 & 70 \\
(\%) & 11.0 & 11.0 & 11.0 & 11.0 & 11.0 & 11.0 & 11.0 & 11.0 & 11.0 & 11.0 \\
\hline
\end{tabular}

\section{$3 \quad$ Material properties}

The CPB from Raleigh mine has four components: tailing, sand, cement and water. The tailings were recovered from selected location in the tailings storage facility. The sand was transported from a quarry. It is quartz sand which is normally used as construction sand. Both tailings and sand from the site were already pre-screened from large rocks and lumps. Ordinary Portland Cement (OPC) was used as binder. The mixing water was obtained from the site groundwater, which contains extremely high amount of salts (hypersaline), having a total dissolved solids (TDS) of 103,000 ppm. As comparison, suitable mixing water for concrete purposes has TDS of less than 2,000 ppm (Steinour, 1960; CCAA Australia, 2007) and the mandatory limit of the TDS is 50,000, according to ASTM C1603. However, this factor was already taken into consideration in the CPB mix design.

The CPB had an average density of $18.8 \mathrm{kN} / \mathrm{m}^{3}$, with a solids content of about $74-75 \%$. The solid mass composed of $65 \%$ tailings, $30 \%$ sand, and $5 \%$ and $4 \%$ OPC by weight (the detail is given in Table 1 and Table 2). Materials samples from the stockpile were brought to the laboratory for the particle size analysis. The sand particles have an average particle diameter $\left(d_{50}\right)$ of $0.56 \mathrm{~mm}$ and the uniformity coefficient $\mathrm{Cu}$ $\left(=d_{60} / d_{10}\right)$ of 3.6, and all are finer than $4.75 \mathrm{~mm}$, with an insignificant amount finer than $0.075 \mathrm{~mm}$. The tailings have an average particle diameter $\left(d_{50}\right)$ of $0.054 \mathrm{~mm}$ with uniformity coefficient $\mathrm{Cu}$ of 41 , and more than $50 \%$ of particles are finer than $0.075 \mathrm{~mm}$. The combination of tailings and sand produces particles with an average particle diameter $\left(d_{50}\right)$ of $0.124 \mathrm{~mm}$ with uniformity coefficient $\mathrm{Cu}$ of 50.6. The $\mathrm{Cu}$ values indicate that the combination of tailings and sand is less uniform than tailings only. The combined materials have particles $40 \%$ finer than $0.075 \mathrm{~mm}$. The particle size distribution (PSD) of the tailings, the sand, and the corresponding proportional combination of tailings and sand are shown in Figure 5 . Note that these PSDs represent the PSDs of the samples from the stockpile, which indicate the overall PSDs of the materials used in the backfilling experiments. The PSD was obtained using sieve and hydrometer analyses according to ASTM D422. In addition, the specific gravity (Gs) of the tailings, the sand, and the OPC are 2.79 and 2.67, and 3.2 respectively. The solid mixture has an equivalent specific gravity of 2.77 . According to the classification of Potvin et al. (2005), the paste fill should contain at least $15 \%$ passing 20 microns, as indicated by filled circles in Figure 5 . This is required in order to retain the water to achieve reliable paste flow. On the other hand, hydraulic fill requires a maximum $10 \%$ of particles finer than 10 microns to achieve adequate permeability, as indicated by solid circles in Figure 5 . Thus, the combination of Raleigh 
mine tailings and sand falls into the paste category. Note that the two limiting points (paste and hydraulic fill) are actually the same PSDs. That is, a typical PSD trend plot carried through the two points of 20 and 10 micron. It is still a contention between the Canadian typical PSD of $8 \%$ less than 20 micron for hydraulic fill (permeability) and what has been used in Australia. The average yield stress of the CPB was 240 Pa and the average Unconfined Compressive Strength (UCS) was $210 \mathrm{kPa}$ after four days of curing.

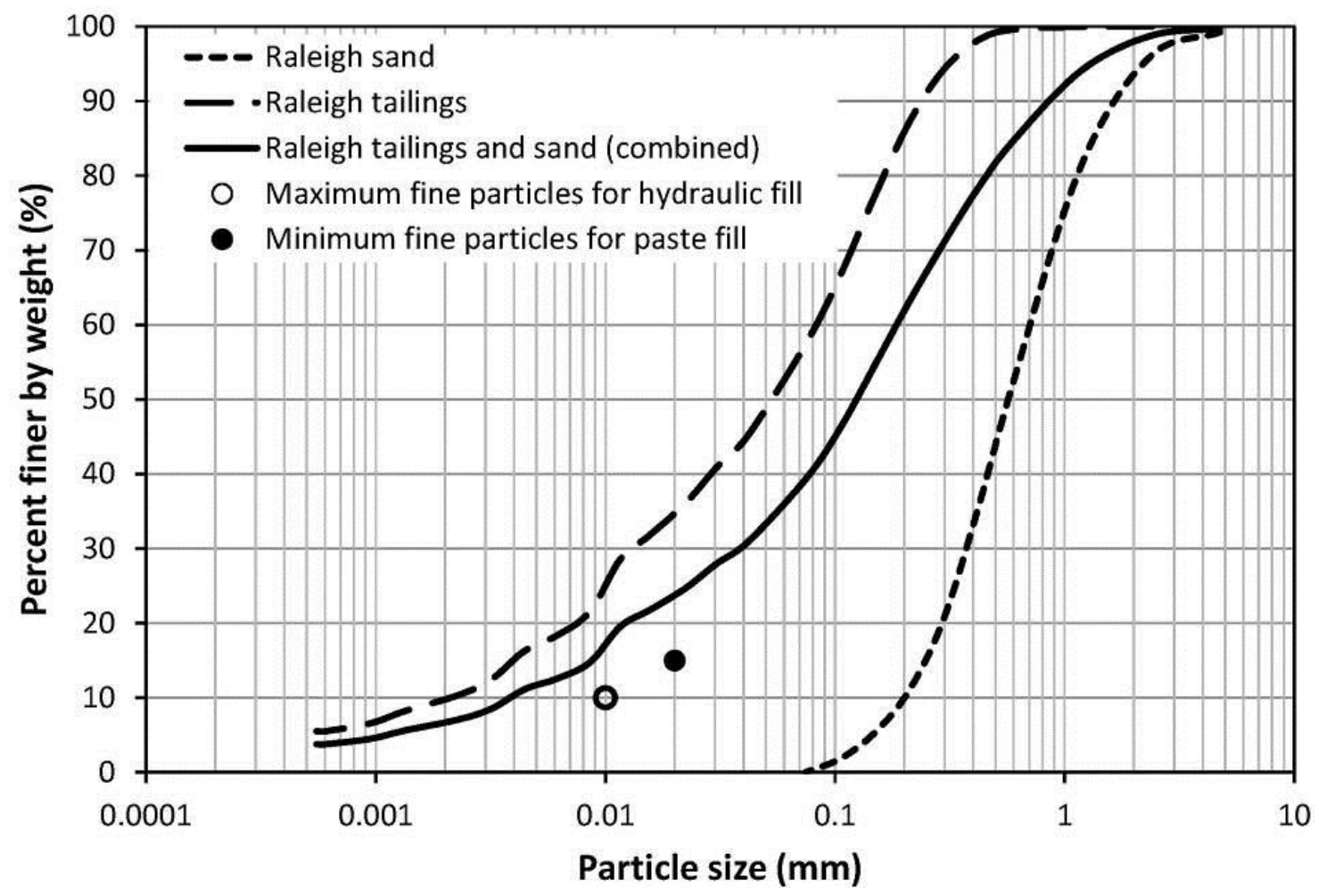

Figure 5 Particle size distributions of Raleigh mine materials

\section{$4 \quad$ Results and discussion}

\subsection{Stope 1}

The pore water pressure measurement at the base (location 1) is shown in Figure 6(a). The figure also shows the geostatic pressure at the base, $\sigma_{b}$, which is estimated as:

$$
\sigma_{b}=\gamma_{c p b} z
$$

Where:

$$
\begin{aligned}
\sigma_{b}= & \text { estimated geostatic stress at the base of the stope. } \\
\gamma_{c p b}= & \text { unit weight of the CPB. } \\
z \quad= & \text { depth from the surface of the paste fill to the stope base (estimated from the rate of rise } \\
& \text { during the filling and filling time). }
\end{aligned}
$$




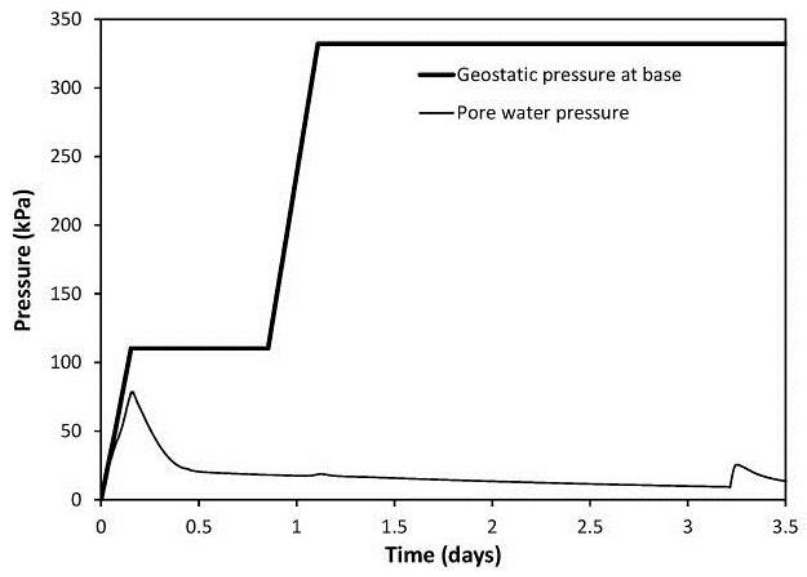

(a)

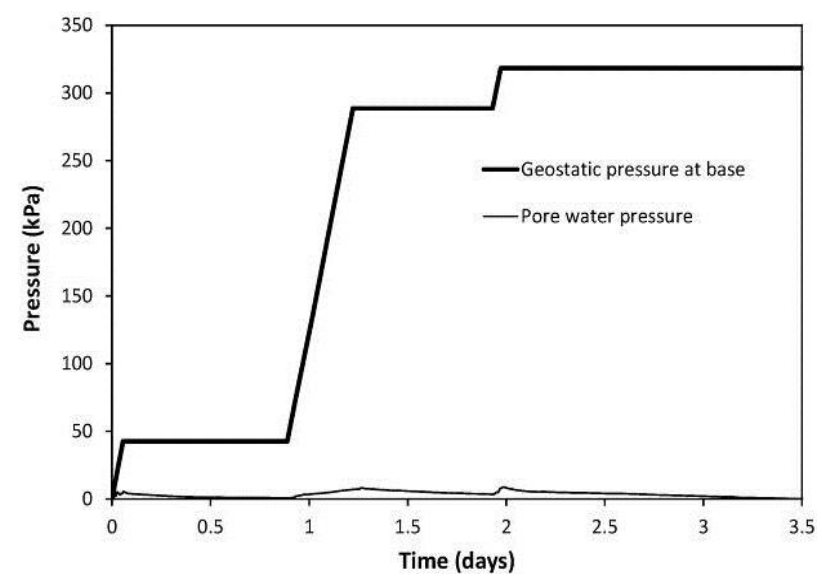

(c)

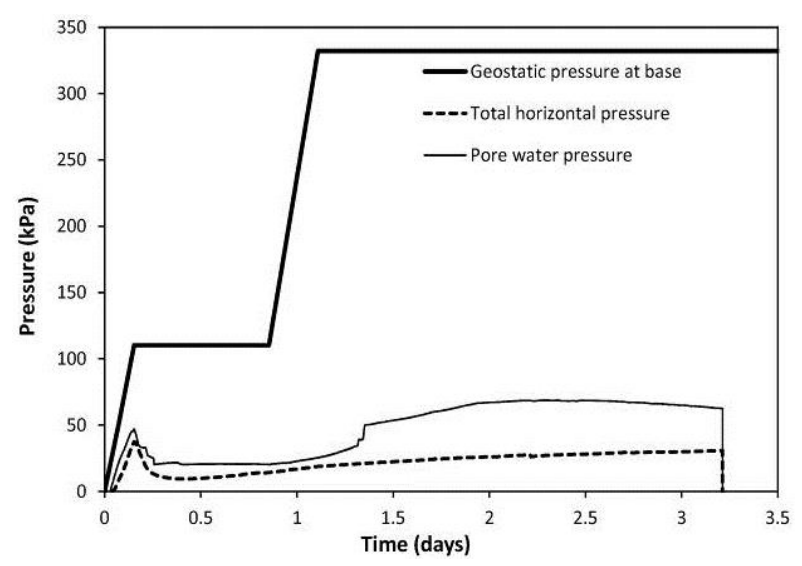

(b)

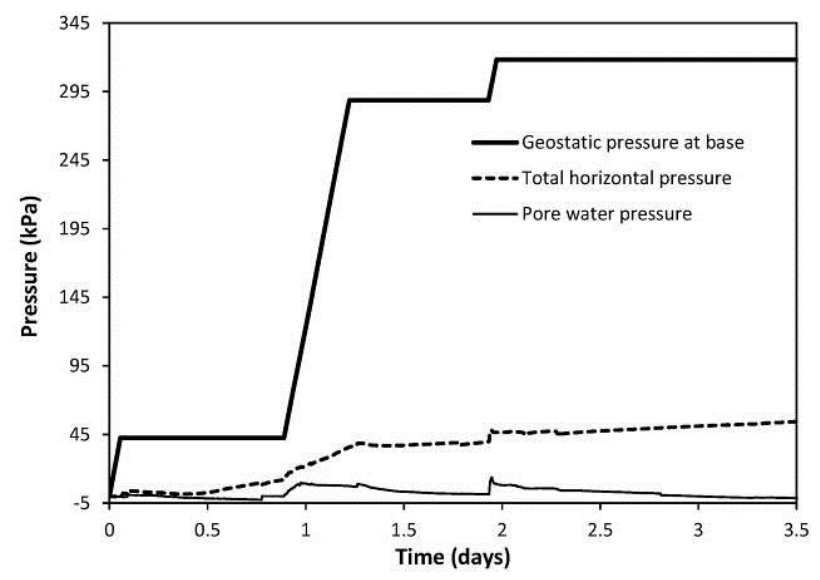

(d)

Figure 6 (a) Pore water pressure at base in stope 1; (b) Pore water pressure and total horizontal pressure at barricade in stope 1; (c) Pore water pressure at base in stope 2; (d) Pore water pressure and total horizontal pressure at barricade in stope 2

The geostatic pressure curve is superimposed with the pore water pressure curves in order to be used as a reference to indicate sequences in the filling process and also for comparison purposes.

In Figure 6(a), the pore water pressures at the base of the stope (location 1 ) increase during the first filling until a maximum value of $80 \mathrm{kPa}$ (at the time when the first filling was completed). The estimated geostatic pressure was $110 \mathrm{kPa}$. The increase in pore water pressure corresponds to the geostatic pressure rate of increase. It signifies that there is insignificant consolidation taking place during the filling process, because of the rapid filling rate. The paste was still in a liquid form, and negligible effective stresses had been generated as yet. Thus, boundary friction (arching) was negligible. According to Fahey et al. (2009), the degree of arching depends heavily on the generation of effective stress indicated by the value of the mobilised friction angle.

The pore water pressure at location 1 decreases soon after the first filling stopped. This is due to the consolidation process, where the excess pore water dissipates to the surrounding boundary. Note that selfdesiccation (albeit minor) (Helinski et al., 2007) might have begun at the same time. Theoretically, there is only one drainage boundary (one-way drainage) in stope 1, which is towards the surface of the fill. However, in reality, fissures in the surrounding rocks and at the barricade can intensify the rate of consolidation. The pore water pressure reduces to $25 \mathrm{kPa}$ in 0.4 days. After 0.4 days, the pore water pressure curve at location 1 diminishes at a slower rate. At this stage, much of the excess water pressure has already dissipated due to consolidation and the self-desiccation process. 
The second filling causes virtually no increase in the pore water pressure, with only a spike of about $0.6 \mathrm{kPa}$, which is insignificant. The consolidated plug of $6 \mathrm{~m}$ clearly achieved the required effect, i.e. reducing additional pore water pressure generation upon second filling. After the second filling terminated, the pore water pressure curve kept on reducing with the same rate as before the spike.

After the third day ( 3.2 days in the curve), there was a production blasting event that took place near the barricade. The pressure from the blasting was detected by the sensor, which indicated an increase of the pore water pressure of $12 \mathrm{kPa}$. The blasting pressure did not damage the sensor. The excess pore water pressure rapidly diminished after the blasting event.

Figure $6(\mathrm{~b})$ depicts the pore water pressure and total horizontal pressure measurements at the barricade in stope 1. Both sensors show an increase for a few hours after the first filling commenced. The value of the total horizontal pressure and the pore water pressure at the end of the first filling were 37 and $46 \mathrm{kPa}$, respectively, which is significantly lower than the geostatic stresses. The total horizontal pressure reduces sharply after the end of the first filling, to $10 \mathrm{kPa}$ at 0.3 days, but then increased at a slow rate even before the second filling started. The second filling did not affect the reading significantly. After the second filling, there is still a slight increase in horizontal pressure, although there was no more 'known' additional load. Similar results were reported in other literature (Thompson et al., 2009, 2011). The increase in pressure measured after the completion of the backfilling can generally be attributed to specific mining events in the vicinity of the backfilled stope. This could be true since there were activities such as blasting, flushing the pipelines with water, and drilling, which added water to the stope. A comprehensive computer modelling exercise in three dimensions is being carried out to investigate this phenomenon, and the result will be published subsequently.

The pore water pressure did not show a significant increase until the second filling started. It increased sharply until the end of the second filling, reaching a value of $50 \mathrm{kPa}$. The pore water pressure kept increasing at a slower rate until it reached a peak of $68 \mathrm{kPa}$ after two days. However, after two days the pore water pressure diminished slowly, as shown by the parabolic curve. At the production blasting event (at 3.2 days) near the barricade, both the piezometer and stress cell reading dropped significantly due to the physical damage of both sensors.

It is worth mentioning that in Figure $6(\mathrm{~b})$ the reading of the total horizontal pressure is notably lower than the pore water pressure reading after the second filling. This is somewhat unexpected. The reason for this is still uncertain and difficult to explain. It could be due to non-functionality of the sensor, underregistration of the sensor, or the malfunction of another mechanism that remains unexplained. The authors are carrying out further investigation of this particular aspect.

The reading of the temperature obtained from the thermistor inside the sensors show that there was not much fluctuation. The temperature of the paste inside the stope measured between $26-33^{\circ} \mathrm{C}$. The increase of the temperature is due to the cement reaction, which produces heat.

\subsection{Stope 2}

Figure 6(c) shows the plot of pore water pressure measurement at the base of stope 2 against time, including the estimated geostatic pressure at the base. The pore water pressure reached a peak of $5 \mathrm{kPa}$ at the end of the first filling. The estimated geostatic stress at base was $42 \mathrm{kPa}$, equivalent to $2.3 \mathrm{~m}$ of CPB. The low value of pore water pressure is due to the drainage in the barricade. The excess water freely flowed through the lower drainage pipe at the barricade. The pore water pressure diminished slowly until reaching zero value at the end of the first filling. During the second filling, the pore water pressure increases until $7.5 \mathrm{kPa}$ at peak. The increase at peak value was not significant compared to the additional geostatic load of $246 \mathrm{kPa}$. The pore water pressure then decreases at a slow rate down to $3.5 \mathrm{kPa}$. The third filling increased the pore water pressure up to $8 \mathrm{kPa}$, after which it diminishes slowly, reaching zero after 3.5 days.

The plots of total horizontal pressure and pore water pressure against time at the barricade in stope 2 are shown in Figure $6(\mathrm{~d})$. The total horizontal pressure and pore water pressure increased for a few hours after 
the first filling to peak values of 4 and $1.5 \mathrm{kPa}$, respectively. The pore pressure dropped to $-2.5 \mathrm{kPa}$, while the total horizontal pressure diminished to a small value of about $1 \mathrm{kPa}$ and then ramped up. The negative value of the pore water pressure indicates that suction was being generated. This is associated with the effect of the drainage at the barricade. The small negative reading is possible, since the piezometer was fully saturated before use (i.e. no air pockets). At the start of the second filling, the pore water pressure increased to $9 \mathrm{kPa}$ and the total horizontal pressure kept on increasing, with a faster rate than before. The value of the pore water pressure dropped slightly to $7 \mathrm{kPa}$ at the end of the second filling. Then, the value dropped at a slow rate down to $1.5 \mathrm{kPa}$ before the third filling. Meanwhile, the total horizontal pressure kept on increasing up until $37 \mathrm{kPa}$ at the end of the second filling. The third filling increased the total horizontal pressure up to $47 \mathrm{kPa}$, followed by a slow increase up to $53 \mathrm{kPa}$ at 3.5 days. There was no production blasting until 3.5 days in stope 2 . The measured temperature inside stope 2 was between $22^{\circ} \mathrm{C}$ (minimum) and $38^{\circ} \mathrm{C}$ (maximum).

After three days the amount of drained water in the water tank was approximately 500 litres. There were no solids in the tank. The amount of water is relatively small compared to the amount of water that composed the CPB including the flush water, which is approximately $4.7 \times 10^{5}$ litres. However, the excess water (unhydrated) might also permeate to surrounding boundaries (including rock walls and barricade) through crack and fissures, evaporate and dissipate via absorption.

\subsection{Comparison}

Figure 7 shows a comparison of the normalised total horizontal pressure $\left(\sigma_{h} / \gamma H\right)$ at the barricade between stope 1 and stope 2 . The total horizontal pressure $\left(\sigma_{h}\right)$ is normalised with the estimated geostatic pressure $(\gamma \mathrm{H})$. The $\gamma$ is the unit weight of the CPB and $\mathrm{H}$ is the height of embedment above the sensor. The figure shows that the normalised $\sigma_{\mathrm{h}}$ values in stope 1 are greater than stope 2 until about 0.6 days. Then the stope 2 shows higher values. This is due to the consolidation that has occurred in the $6 \mathrm{~m}$ layer of CPB after the first filling in stope 1 . The peak value of $\sigma_{h}$ in stope 1 was $38 \%$ of the geostatic pressure in the first fill. The value drops down to $10 \%$ during the pause period and increases to $14 \%$ soon after the second filling starts. On the other hand, the peak value of $\sigma_{h}$ in stope 2 was about $9 \%$ of the geostatic pressure in the first fill. The value drops down to $4 \%$ and increases to $26 \%$ soon after the second filling starts. The third filling causes a little spike of about 1.5\%. After the last filling, both stope 1 and stope 2 show an increase at a small rate.

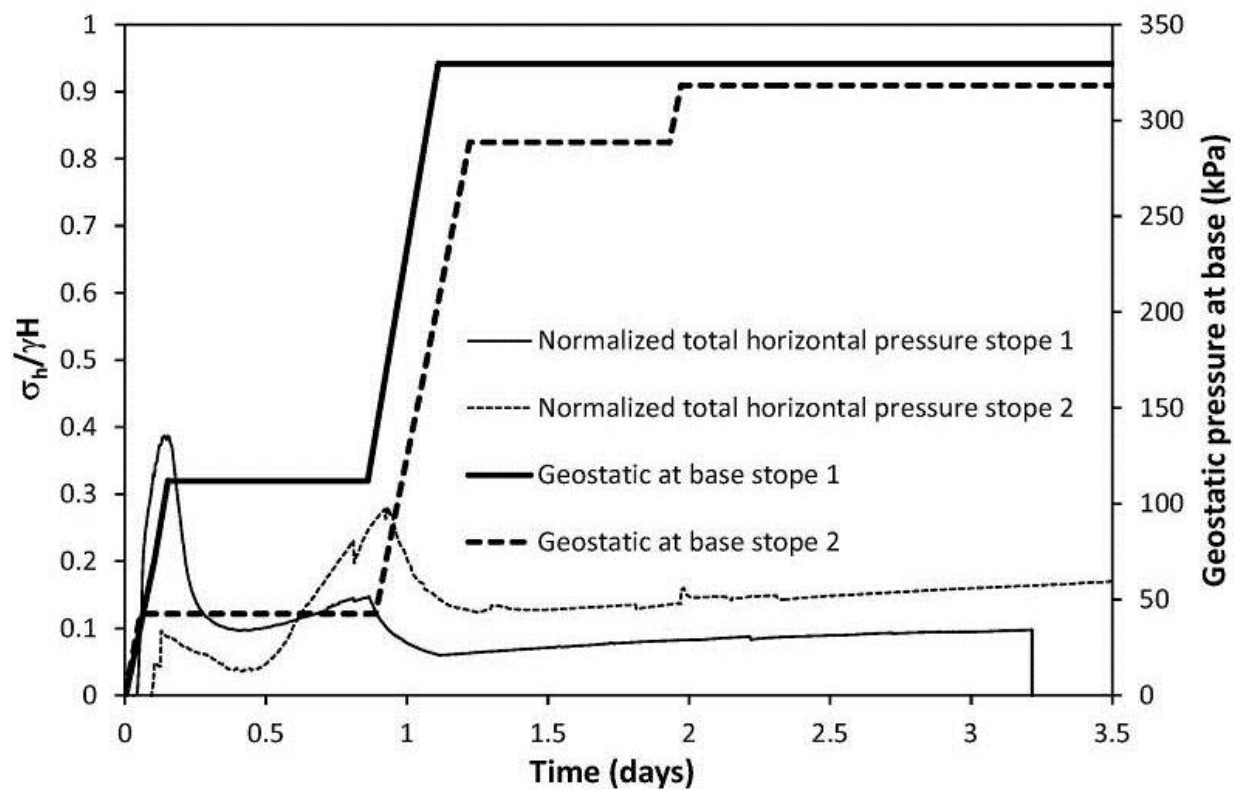

Figure 7 Normalised total horizontal pressures at the barricade 
The normalised pore water pressures $(\mathrm{u} / \gamma \mathrm{H})$ at the base and at the barricade are shown in Figures $8(\mathrm{a})$ and $8(b)$, respectively. A rapid increase of normalised pore water pressures is shown at the base as a result of rapid filling. The peak values are 95 and $60 \%$ for stope 1 and stope 2, respectively. The values decrease towards the end of the filling. The curves drop significantly during the first half of the pause period and diminish at a slower rate during the second half of the pause period. The normalised pore water pressure at stope 1 reached zero after three days while the stope 2 reached $3 \%$ and increased about $4 \%$ due to the effect of production blasting.

At the barricade, the normalised pore water pressure for stope 1 reached peak values of $67 \%$ and $4 \%$ after the first filling. The response for stope 2 is not spontaneous since the drainage effectively removes water during the first filling. The pipes were not blocked by consolidated CPB. The normalised pore water pressure value for stope 2 decreases down to $-6 \%$ before the second filling. Then, it increases due to the second filling up to $8 \%$ and diminishes slowly to almost $0 \%$. A spike of $4 \%$ arises due to the third filling. The stope 1 decreases significantly down to $21 \%$ at 0.25 days then flattens until the second filling starts. The second filling reduces the normalised pore water pressure to $8 \%$ and then increases again up to $21 \%$ after two days.



(a)

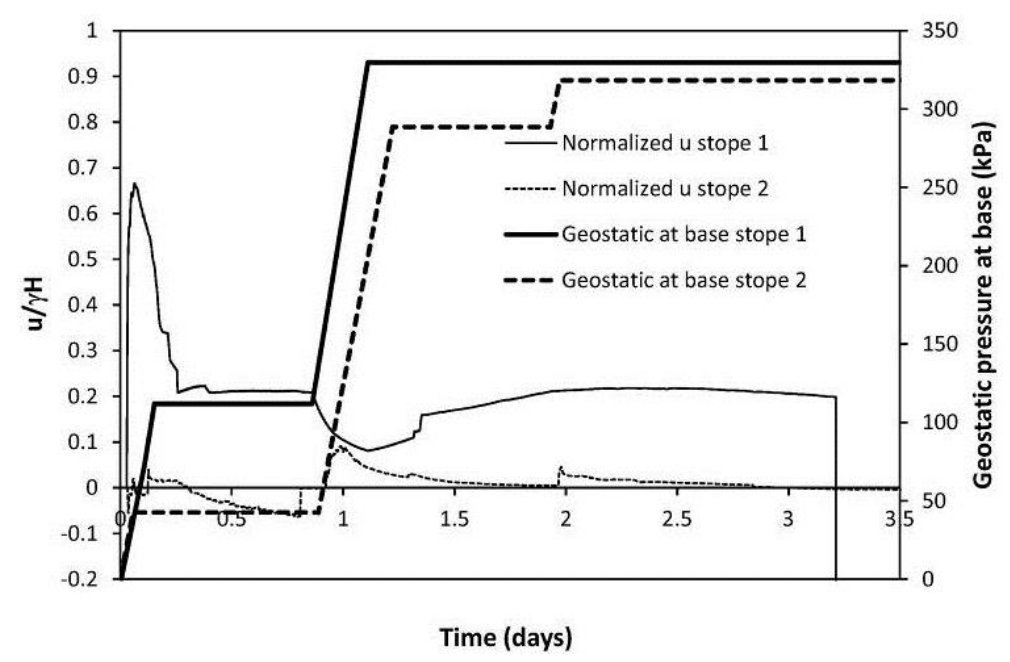

(b)

Figure 8 (a) Normalised pore water pressures at base; (b) Normalised pore water pressures at barricade 


\section{$5 \quad$ Conclusions}

Full-scale observations have been carried out in two operating stopes at Raleigh mine (underground), Western Australia. The observations compare the behaviour of CPB between a stope with and without a drainage system at the barricade. It was found that the drainage system effectively reduced the total horizontal stress and the pore water pressure. Normalised total horizontal pressure and normalised pore water pressure were computed. It is shown that the normalised total horizontal pressure and the normalised pore water pressure inside the stope with the drainage are overall lower than those inside the stope without the drainage. At the barricade, the normalised pore water pressure at the stope with the drainage is $63 \%$ lower than the stope without the drainage. At the base, the normalised pore water pressure at the stope with the drainage is $35 \%$ lower than the stope without the drainage. The pore water pressure can drop to negative values at the stope with the drainage, which indicates the presence of suction. The normalised total horizontal pressure at the barricade with the drainage system is $29 \%$ lower than in the stope without the drainage. There was only a relatively small quantity of water drained from the stope to reduce such pressures.

Drainage provision at the barricade is not universal, perhaps because of the additional time required and added costs that are incurred. This study has emphatically demonstrated the benefits of providing adequate drainage, and furthermore indicated that the volume of water that is needed to be drained is relatively small, meaning there is not necessarily a need for the provision of extensive measures to manage large volumes of drainage water. The reduced barricade stresses could lead to significant savings in cement costs in future stopes, a possibility that is currently being investigated through further field measurements.

\section{Acknowledgements}

The authors acknowledge funding provided by an ARC Linkage Grant (LP100200173) in collaboration with Barrick (Australia Pacific) Limited. The authors would also like to thank Matthew Helinski for advice in initiating the project. Special thanks are given to Russ Evans, Farhan Hafeez, Hendrik Esterhuizen and other Barrick staff for their collaboration in this project.

\section{References}

Belem, T., Harvey, A., Simon, R. and Aubertin, M. (2004) Measurement and prediction of internal stresses in an underground opening during its filling with cemented fill, in Proceedings Fifth International Symposium on Ground Support, Ground Support in Mining and Underground Construction, E. Villaescusa and Y. Potvin (eds), 28-30 September 2004, Perth, Australia, Balkema, Rotterdam, pp. 619-630.

CCAA Australia (2007) Cement Concrete and Aggregates Australia. Use of recycled water in concrete production, CCAA Report, CCAA, Australia.

Clayton, C.R.I. and Bica, A.V.D. (1993) The design of diaphragm-type boundary total stress cells, Geotechnique, Vol. 43(4) 2002, pp. 523-535.

Fahey, M., Helinski, M. and Fourie, A. (2009) Some aspects of the mechanics of arching in backfilled stopes, Canadian Geotechnical Journal, Vol. 46, pp. 1322-1336.

Fahey, M., Helinski, M. and Fourie, A. (2011) Development of specimen curing procedures that account for the influence of effective stress during curing on the strength of cemented mine backfill, Geotechnical and Geological Engineering, Vol. 29, pp. 709-723.

Fourie, A.B., Fahey, M. and Helinski, M. (2007) Using effective stress theory to characterize the behaviour of backfill, in Proceedings 9th International Symposium on Mining with Backfill (Minefill 2007), F. Hassani and J. Archibald (eds), 29 April-2 May 2007, Montreal, Canada, Canadian Institute of Mining, Metallurgy and Petroleum, Canada.

Grabinsky, M.W. and Bawden, W.F. (2007) In situ measurements for geomechanical design of cemented paste backfill systems, in Proceedings 9th International Symposium on Mining with Backfill (Minefill 2007), F. Hassani and J. Archibald (eds), 29 April2 May 2007, Montreal, Canada, Canadian Institute of Mining, Metallurgy and Petroleum, Canada.

Helinski, M., Fahey, M. and Fourie, A. (2011) Behavior of cemented paste backfill in two mine stopes, Journal of Geotechnical and Geoenvironmental Engineering, Vol. 137, pp. 171-182.

Helinski, M., Fourie, A., Fahey, M. and Ismail, M. (2007) Assessment of the self-dessication process in cemented mine backfills, Canadian Geotechnical Journal, Vol. 44, pp. 1148-1156.

Landriault, D.A., Brown, R.E. and Counter, D.B. (2000) Paste backfill study for deep mining at Kidd Creek, CIM Bulletin, Vol. 93, pp. 156-161. 
Le Roux, K., Bawden, W.F. and Grabinsky, M.F. (2005) Field properties of cemented paste backfill at the Golden Giant mine, Mining Technology, Transactions of the Institute of Mining and Metallurgy A, Vol. 114, pp. A65-A80.

Potvin, Y., Thomas, E. and Fourie. A.B. (eds) (2005) Handbook on Mine Fill, Australian Centre for Geomechanics, Perth, 179 p.

Rankine, R.M. and Sivakugan, N. (2007) Geotechnical properties of cemented paste backfill from Cannington Mine, Australia, Geotechnical and Geological Engineering, Vol. 25, pp. 383-393.

Sivakugan, N., Rankine, R.M., Rankine, K.J. and Rankine, K.S. (2006) Geotechnical considerations in mine backfilling in Australia, Journal of Cleaner Production, Vol. 14, pp. 1168-1175.

Steinour, H.H. (1960) Concrete mix water - How impure can it be? Portland Cement Association Journal, Vol. 3, pp. 32-50.

Talesnick, M. (2004) Measuring soil contact pressure on a solid boundary and quantifying soil arching, Geotechnical Testing Journal, Vol. 28, pp. 1-9.

Taylor, D.W. (1947) Pressure distribution theories, earth pressure cells investigations and pressure distribution data, US Army Engineer Waterways Experiment Station, Vicksburg.

Thompson, B.D., Bawden, W.F. and Grabinsky, M.W. (2011) In situ measurements of cemented paste backfill at the Cayeli Mine, Canadian Geotechnical Journal, Vol. 49, pp. 755-772.

Thompson, B.D., Grabisnky, M.W. and Bawden, W.F. (2009) In-situ measurements of cemented paste backfill in long-hole stopes, in Proceedings of the Third CANUS Rock Mechanics Symposium, Toronto. 